\title{
PEMBERDAYAAN MASYARAKAT PESISIR DAN PANTAI DALAM MENINGKATKAN PRODUKTIFITAS DAN EFISIENSI DI SENTRA INDUSTRI KAPAL KAYU DI KABUPATEN BATANG
}

\author{
Ari Wibawa Budi Santosa ${ }^{1)}$, Bambang Sri Waluyo ${ }^{2)}$, Sri Pujiyanto ${ }^{3)}$, Sri Rahayu Tri Astuti ${ }^{4}$ \\ ${ }^{1)}$ Jurusan Teknik Perkapalan, Fakultas Teknik, Universitas Diponegoro \\ ${ }^{2)}$ Jurusan D3 Teknik Perkapalan, Fakultas Teknik, Universitas Diponegoro \\ ${ }^{3)}$ Jurusan Biologi, Fakultas Sains dan Matematika, Universitas Diponegoro \\ ${ }^{4)}$ Jurusan Manjemen, Fakultas Ekonomika dan Bisnis, Universitas Diponegoro \\ Email: a wisilmiw@yahoo.com
}

\begin{abstract}
Abstrak
Proses pembuatan kapal di Galangan Kapal Kayu CV Laksana Abadi Batang masih menggunakan cara tradisional, saat ini mengalami kesulitan untuk memenuhi jumlah pesanan yang banyak. Program KKNPPM ini untuk membantu para pengrajin kapal kayu tradisional di Batang melalui menerapkan teknologi yang lebih modern melalui penggunaan aplikasi software perkapalan seperti Delfship dan Maxsurf. dengan menggunakan software tersebut diharapkan pengrajin kayu tradisional mampu mempercepat proses produksi dari 120 hari/ kapal menjadi 90 hari/kapal dan juga kapal kayu yang dibuat akan lebih bagus. Dalam program KKNPPM ini mahasiswa juga harus mengenalkan pada masyarakat pesisir di Batang tentang kebersihan lingkungan. Produsen dan Pengrajin kapal kayu tradisional diberikan penyuluhan K3LH, menjaga kebersihan lingkungan dari limbah buang kapal yang dapat mencemari laut sekitar. Oleh karena itu, akan diterapkan pada setiap kapal kayu yang akan dibuat teknologi tepat guna OWS (oil water Separator). Dengan menerapkan teknologi tepat guna OWS, penanaman mangroove diharapkan dapat meminimalisir pencemaran laut karena limbah buang kapal kayu.
\end{abstract}

Kata Kunci : Galangan, Lingkungan, Pesisir, Mangroove, Produksi

\section{PENDAHULUAN}

\subsection{Latar Belakang}

Kabupaten Batang memiliki garis pantai yang cukup panjang, yaitu $38,73 \mathrm{~km}$ garis pantai tersebut terbentang dari Kecamatan Batang, Kecamatan Tulis, Kecamatan Subah, Kecamatan Limpung dan Kecamatan Gringsing dengan demikian sebagian besar penduduk di Kecamatan tersebut berada di jalur Pantai Utara, yang merupakan daerah pesisir yang bermata pencaharian di bidang perikanan laut seperti nelayan, pengelola ikan laut dll. (www.batang.go.id). Diwilayah pesisir kabupaten Batang terdapat potensi yang dapat dikembangkan sehingga dapat menjadi aset yang berharga bagi bangsa yaitu para pembuat kapal tradisional.

Artinya sebelum dibangun harus sudah ada Gambar kerja dan spesifikasi tebal yang jelas. Selama ini para pengrajin kapal batang membuat kapal tanpa ada gambar. Sehingga pada kegiatan KKN ini akan di upayakan agar para pengrajin kapal mampu membaca gambar bahkan menggambar dengan bantuan Software perkapalan.
Menurut hasil akhir penelitian inventarisasi Regristrasi Kapal Nelayan pantura Jawa tengah (IRK, 2003/2004, KKP) jumlah kapal nelayan yang beroperasi di sepanjang pantai utara Jawa Tengah kurang lebih 19.652 buah dari berbagai type dan ukuran. Dari jumlah tersebut di Sendang Sekucing terdapat 276 kapal dan perahu, yang terbagi sebagai berikut ; $70 \%$ terdiri dari perahu-perahu sopek yang mempunyai ukuran yang hampir sama dan menggunakan mesin tempel dari berbagai merk dan jumlah terbanyak adalah Dongfeng \& Kubota.

Di Batang sebagai sentra industri kapal kayu terdapat beberapa $\mathrm{CV}$,seperti :

CV. Laksana Abadi, CV.Nuh Marine, CV.Anugrah,CV.Berkah Mandiri, CV.Maju Jaya, CV. Gematu Mitra Bahari, CV. Karya Sejahtera. Dilihat dari segi produktifitas galangan, terbukti CV. Laksana Abadi sebagai galangan kapal tradisional pada tahun 2013 mampu memproduksi kapal berjumlah 18 unit dalam jangka waktu 12 bulan. Kapal-kapal yang dibangun di galangan Laksana Abadi memiliki variasi ukuran yang beraneka ragam, mulai dari kapal dengan ukuran lunas 10 
meter, 15 meter, sampai ukuran lunas 25 meter. Produk kapal mereka memiliki beberapa keunggulan dibanding kapal tradisional lain , yaitu: stabilitas yang baik dan mesin utama berada di dalam (In board engine). .

Pengrajin kapal kayu pada Kabupaten Batang walaupun memiliki pengetahuan tentang rancang bangun kapal tetapi belum memiliki teknik rancang bangun kapal secara modern ini dapat terlihat pada saat pembangunan kapal tidak dilengkapi gambar teknik mengenai lambung kapal maupun gambar teknik lainnya ini terlihat hampir disemua pengrajin di daerah Batang belum memiliki pengetahuan tentang gambar teknik kapal yang disebabkan juga karena tingkat pendidikan para pengrajin kapal kayu maupun pengetahuan pembangunan yang diperoleh secara turun temurun menyebabkan pengetahuan tersebut hanya berdasarkan pengalaman yang diturunkan secara langsung dimana pengalaman terdahulu pun belum memiliki pengetahuan tentang gambar teknik lambung kapal.

Pengrajin kapal kayu yang terdapat di Batang memiliki corak yang sangat spesifik terlihat dari bentuk lambung kapal Batang akan sangat berbeda dengan bentuk lambung tipe daerah Juwana sehingga dapat ditarik kesimpulan bahwa bentuk lambung kapal yang dibuat oleh pengrajin kayu kapal Batang akan meiliki kesamaan dari pengrajin satu dan yang lainnya. Selain CV. Laksana Abadi terdapat juga usaha sejenis yang tidak jauh mitra pertama yaitu PT. Satria Laksana Bahari yang bergerak dibidang pembuatan kapal kayu yang memiliki produktifitas yang lebih kecil dikarenakan masih relatif baru berdiri di tahun 2012. PT. Satria Laksana Bahari terletak tidak jauh dari CV. Laksana Abadi dikarenakan terletak di daerah yang sama di daerah Kelurahan Karangasem Utara Kecamatan Batang. PT. Satria Laksana Bahari dapat membuat kapal kayu dari tipe 10 GT hingga $100 \mathrm{GT}$

Armada kapal perikanan nasional, sampai dengan saat ini, masih didominasi oleh berbagai jenis perahu dan kapal penangkap ikan tradisional (disebut dengan "kapal ikan tradisional"). Umumnya, kapal ikan tradisional terbuat dari kayu dengan ukuran kurang dari 30 GT dan dibangun oleh galangan atau perajin kapal kayu tradisional, sehingga mempunyai corak yang spesifik untuk masingmasing daerah. Karena sifatnya tradisional, maka acuan dalam pelaksanaan pembangunannya tidak berdasarkan gambar rancang-bangun (design) dan spesifikasi teknis yang lengkap, melainkan berdasarkan pengalaman yang dimiliki secara turuntemurun dan mengikuti sistem tradisi masyarakat setempat (Oktavian, 2008). Sehingga proses pembuatan dapat dikatakan menggunakan metode masih sangat tradisional dan Kepercayaan mereka terhadap perkembangan teknologi sangatlah rendah ini terlihat dari cara pembangunan kapal masih tradasional dimana kapal dibuat dari lambung dibentuk kemudian dibuatlah gading kapal padahal ini terbalik dari konsep bangunan kapal baru dimana pertama yang dilakukan saat awal pembangunan kapal baru adalah membentuk gading kapal dahulu kemudian membentuk lambung kapal dengan menyesuaikan dari gading kapal tersebut. Hal ini menyebabkan perlunya transfer pengetahuan tentang pembanguan kapal secara modern kepada perajin kapal di kabupaten Batang terutama dibidang rancang bangun kapal agar produksi kapal bisa lebih cepat dan efisien yang kemudian produksi pembuatan kapal tradisional bisa lebih banyak yang dapat meningkatkan mutu hidup masyarakat dan nelayan setempat. Masyarakat pesisir yang

membangun kapal tanpa adanya proses perencanaan gambar teknik membuat mereka tidak pernah mengetahui secara pasti bagaimana karakteristik lambung kapal mereka serta kelemahan desain lambung kapal yang dibangun oleh mereka. Sehingga perlunya institusi pendidikan untuk dapat mentransfer teknologi pembangunan kapal secara modern sehingga kontribusi ini dapat benar-benar dimanfaatkan oleh pengrajin kapal tradisional, khususnya untuk wilayah Kabupaten Batang Jawa Tengah.

Selain itu, untuk meningkatkan kesadaran masyarakat akan kebersihan lingkungan laut, karena pada saat reparasi kapal tradisional dibutuhkan waktu yang lama membuat limbah buang kapal mengotori lingkungan lautnya. Maka diperlukan teknologi tepat guna OWS(oily water separator). Berfungsi untuk memisahkan oli dengan air yang dibuang ke laut, agar lingkungan tetap terjaga kebersihannya. 


\subsection{Perumusan Masalah}

Adapun permasalahan yang dihadapi oleh perajin kapal tradisonal mitra secara rinci yang menjadi prioritas adalah sebagai berikut :

1. Teknik rancang bangun kapal kayu di kabupaten Batang belum memiliki gambar teknik pada kapal bangunan barunya.

2. Kurangnya pemahamanan tentang teknik pembangunan kapal secara modern terutama keutamaan gambar teknik.

3. Tidak adanya referensi kapal bangunan baru dengan gambar teknik menyebabkan perajin tidak mengetahui karateristik kapal yang dibuat.

4. Perlunya pengetahuan mengenai konsep bangunan kapal baru yang tepat dan benar.

5. Waktu yang lama saat reparasi kapal tradisional membuat limbah buang dari kapal tradisional mencemari laut sekitar, maka dibutuhkan teknologi tepat guna Oil Water Separator.

6. Abrasi pantai.

\subsection{Tujuan Dan Manfaat}

Tujuan utama dan manfaat yang dapat diperoleh dari kegiatan ini adalah sebagai berikut.

1) Meningkatkan pengetahuan pekerja galangan kapal kayu dalam bidang perancangan kapal menggunakan software.

2) Meningkatkan kesadaran masyarakat akan pentingnya tanaman mangrove untuk menjaga kondisi pesisir.

3) Memberi pengetahuan para nelayan dan operator kapal ikan tentang manfaat dan penggunaan alat oily water separator dalam mengurangi tingkat pencemaran air laut.

\section{TINJAUAN PUSTAKA}

Beberapa sumber pencemaran minyak antara lain : dari ladang minyak dibawah dasar laut baik melalui rembesan maupun kesalahan pengeboran pada operasi minyak lepas pantai, kecelakaan pelayaran seperti misalnya kandas, tenggelam dan tabrakan kapal-kapal tanker atau barang yang mengangkut minyak / bahan bakar, operasi kapal dimana minyak terbuang kelaut sebagai akibat dari pembersihan tangki atau pembuangan air ballast dan lain lain, kapal-kapal selain tanker melalui pembuangan air bilga ( got ), operasi terminal pelabuhan minyak dimana minyak dapat timpah pada waktu memuat / membongkar muatan atau pengisian bahan bakar ke kapal, limbah pembuangan refinery, dan sumber-sumber darat misalnya minyak lumas bekas atau cairan yang mengandung hidrokarbon (Adi, 2008).

\subsection{Prinsip dan Kerja OWS :}

Air got dihisap oleh Bilge pump diteruskan ke bilge separator ( stage II ) yang bercampur dengan minyak. Gravity Disck dalam bilge separator yang berputar secara sentrifuse oleh motor penggerak yang mengakibatkan memisahnya bagian-bagian berat dengan lain-lainnya yang ringan. karena pengaruh berat jenis antara air got dengan minyak kotor, maka minyak kotor terlempar bagian atas, sedangkan bagian air got terlempar kebawah ( pengaruh sentrifugal ).

Minyak tersebut akan mengirim sinyal ke unit control mengakibatkan selenoide valve bekerja, membuka membran piston valve, sehigga minyak kotor masuk ke sludge tank,s sedangkan air got masuk ke coaliser ( stage II ) ke fillter naik keatas sisi kananmembalik menurun kebawah lewat filtter ke sisi kiri. konsentrasi air got dapat di monitor menggunakan OPM ( Oil Pollution Monitor ) bila konsentrasi menunjukan 15 ppm maka air got di buang kelaut namun bila konsentrasi melebihi dari 15 ppm maka keadaan sistem coaliser secara flushing dengan harapan menurunkan $\mathrm{ppm}$ tersebut normal dengan menurunkan overboard. minyak kotor akan ditampung di sludge tank, selanjutnya di bakar menggunakan Insalator yang mengakibatkan minyak terbakar menjadi gas dan dikarenakan pencemaran minyak tidak diperbolehkan di buang ke laut.

Di Atas Dermaga Pelabuhan Perikanan, Kemungkinan adanya kendala pemasangan pesawat OWS pada kapal 10 - 50 GT, maka dapat disiasati dengan penempatannya diatas dermaga. Dimana, kapal-kapal berukuran 50 GT kebawah dapat membuang dan mengumpulkan limbah air got tersebut kedalam tangki penampung dan selanjutnya akan diproses oleh pesawat OWS yang telah tersedia di dermaga. 


\section{METODE PELAKSANAAN}

Metode pelaksanaan kegiatan ini dalam bentuk sebagai berikut.

\subsection{Persiapan Kegiatan KKN}

Pada kegiatan KKN-PPM ini kegiatan yang diutamakan adalah pengenalan teknologi perkapalan pada masyarakat pengrajin kapal kayu yang masih memabngun kapal secara tradisional maka diharapkan mahasiswa dapat memberikan transfer pengetahuan mengenai proses membangun kapal secara modern, penggunaan gambar teknik pada pembangunan kapal dan aplikaasi teknologi tepat guna OWS. Mahasiswa akan diberikan pembekalan mengenai aspek pengetahuan teknologi perkapalan.

Diharapkan dari pembekalan tersebut maka mahasiswa mampu menerapkan teori perkapalan tidak hanya sebatas di dunia akademik namun mampu melakukan transfer teknologi kepada pengarjin kapal kayu yang masih menggunakan teknologi kapal secara tradisional.

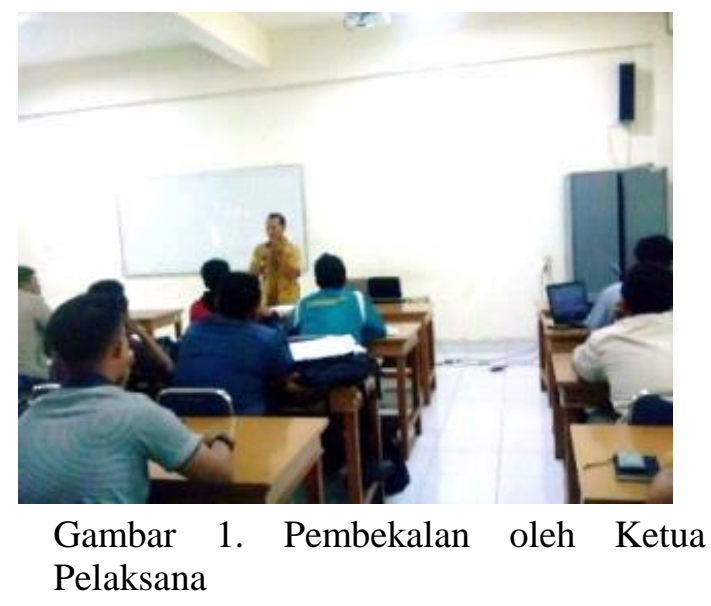

\subsection{Pelaksanaan Kegiatan}

Pada pelaksanaan kegiatan KKN-PPM ini merupakan kegiatan KKN yang terintegrasi dengan LPPM Undip yang merupakan salah satu matakuliah wajib bagi mahasiswa tingkat akhir pada program sarjana. Namun dengan adanya KKNPPM ini maka kegiatan pemberdayaan masyarakat pesisir khususnya pengrajin kapal kayu yang masih tradisional diharapkan terjadinya pembaharuan konsep dari membuat kapal kayu secara tradisional menjadi membuat kapal kayu dengan standar yang baku dan lebih baik(modern).

\subsection{Rencana Keberlanjutan Program KKN- PPM}

Keberlanjutan program KKN-PPM ini sejalan dengan tridharma perguruan tinggi Universitas Diponegoro dimana program KKN merupakan matakuliah wajib yang bisa di integrasikan dengan pengabdian kepada masyarakat pesisir yang masih minim perhatian dari pemerintah terutama nelayan dan pengrajin kapal kayu. Dengan adanya jurusan teknik perkapalan di Undip maka kedepan dapat dilakukan KKN tematik yang sesuai dengan Pola Ilmiah Pokok (PIP) Undip yaitu pemberdayaan masyarakat pesisir pantai yang meliputi nelayan, pengarjin kapal kayu serta pemerintah. Sehingga dengan semakin baiknya armada nelayan akan meningkatkan pula penghasilan nelayan dan meningkatkan pengetahuan masyarakat pesisir tentang teknologi maritim dengan program KKN tematik industri maritim tradisional di Jawa Tengah.

\section{HASIL DAN PEMBAHASAN}

Berdasarkan pelaksanaan KKN PPM Tematik di Desa Karangasem Utara, Kecamatan Batang Kota, Kabupaten Batang, maka hasil yang diperoleh diklasifikasikan tiap kelompok pelaksanaan sebagai berikut.

\subsection{Kelompok 1 (Program Pengenalan Software Perkapalan) \\ Pada rencana awal program pelatihan} diberikan kepada para pekerja galangan yang masih belum mengerti tentang teknologi informasi dan perangkat lunak yang dapat mempermudah proses perancangan kapal. Namun, setelah dibahas lebih mendalam pelatihan diberikan kepada pekerja tertentu di galangan yang benar-benar membutuhkan pengetahuan tersebut seperti bagian perancangan, sasaran lainnya yang menjadi titik berat pelatihan ini adalah para siswa sekolah di kelurahan Karangasem Utara tepatnya di sebuah sekolah kejuruan yang berhubungan dengan ilmu kemaritiman, pertimbangannya adalah bahwa usia remaja adalah usia yang masih semangat mempelajari hal baru. Selain itu usia sekolah terutama tingkat menengah atas adalah generasi yang nantinya akan meneruskan perkembangan dan pembangunan kemaritiman di daerah tersebut termasuk dalam bidang perancangan kapal. 


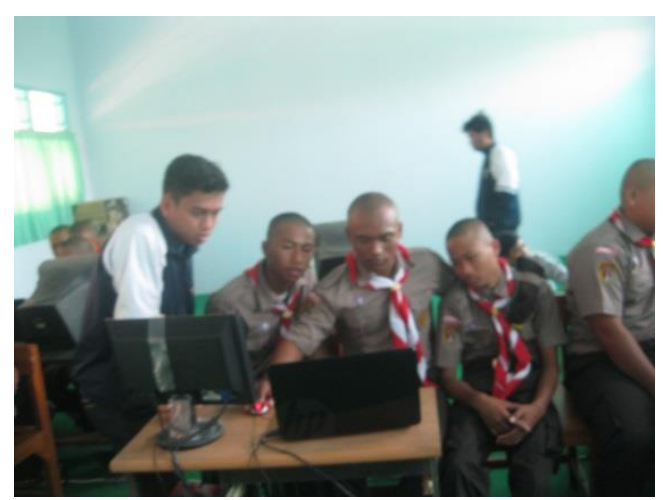

Gambar 2 Sosialisasi ke sekolah pesisir

\subsection{Kelompok 2 (Teknik Penanaman Mangrove dengan Buis Bambu)}

Program penanaman mangrove dilaksanakan di area Pantai Sigandu Kab. Batang yang lokasinya masih disekitar sentra industri kapal batang. Disekiling pantai ini terdapat tanaman tanaman mangrove yang tumbuh disepanjang pantai, namun banyak lahan lahan yang belum ditanami, sehingga lokasi ini sangatlah cocok untuk ditanami mangrove yang difungsikan untuk menahan abrasi pantai. Teknik penanaman mangrove yang dilakukan adalah dengan menggunakan buis bambu sebagai mediatornya.

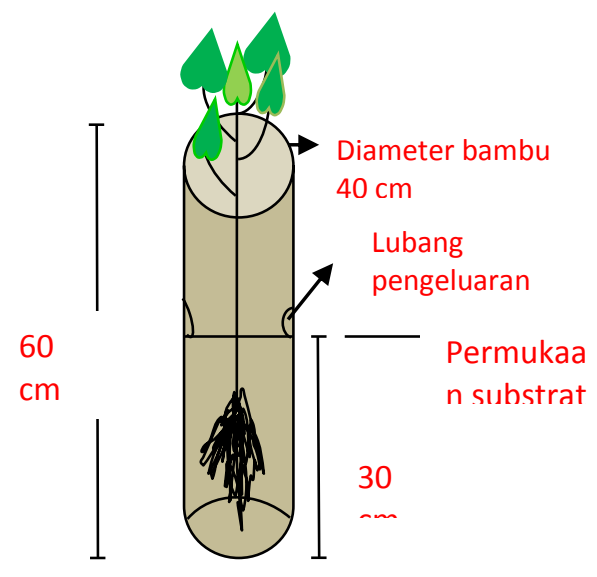

Gambar3. Teknologi buis bambu

\subsection{Kelompok 3 (Pelatihan Penggunaan Alat Oil Water Separator (OWS))}

Program terakhir yaitu pembuatan alat OWS (Oil Water Separator) yang digunakan sebagai pemisah antara air dan oli/ limbah sehingga limbah tersebut sudah disaring telebih dahulu sebelum dibuang kelaut sehingga tidak mencemari laut. program ini bertujuan agar meningkatkan kesadaran warga untuk menjaga lingkungannya.

Dalam pembuatan teknologi OWS ini nanttinya akan diujicobakan di Tempat pengisian Bahan bakar kapal. Hal ini cocok digunakan karena banyak kapal kapal nelayan yang bersandar. Pembuatan OWS ini sudah mencapai tahap finishing dimana hanya tinggal memasang bagian bagian tertentu saja. Tahapan selanjutnya apabila alat sudah jadi maka akan dilakukan uji coba terlebih dahulu apakah hasilnya maksimal untuk menyaring limbahnya.

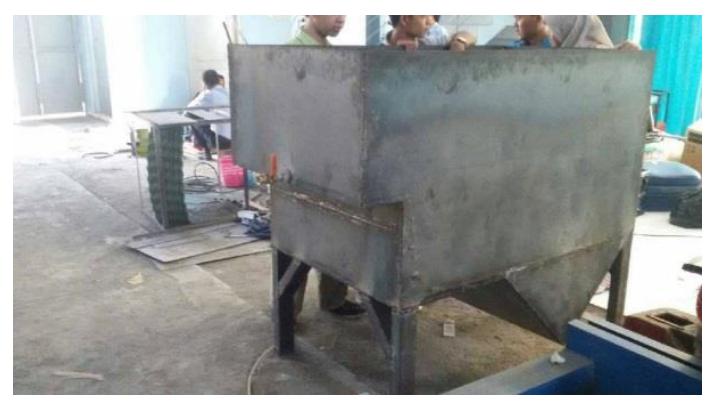

Gambar 4 Pembuatan alat Oily Water Separator

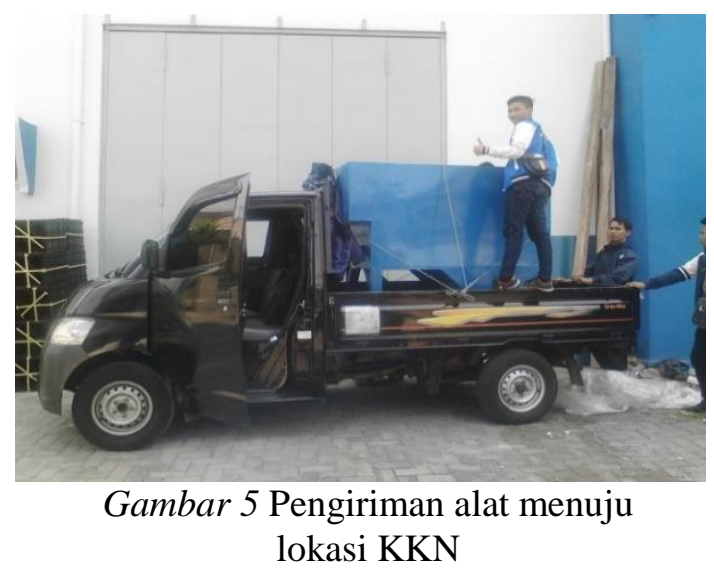

\subsection{Analisa Pembahasan Dalam} Pelaksanaanya, KKN PPM

Pelaksanaan KKN Tematik ini 95\% terlaksana sesuai rencana dan dapat dikatakan berhasil karena masyarakat telah menerapkan berbagai program yang telah diajarkan. Berikut diagram program multidisiplin dan monodisiplin, serta program bantu yang telah dilaksanakan.

Pelaksanaan KKN ini berguna untuk meningkatkan pengetahuan masyarakat baik dari kalangan pekerja maupun pelajar. Harapannya pekerja galangan kapal kayu 
mampu untuk mengembangkan produksi serta skill nya dalam membangun kapal tradisional serta perawatan alat tangkapnya. Selain itu, penghijauan atau perawatan ekosistem alam sekitar juga perlu untuk dilakukan, dengan diadakanya penanaman mangrove guna pencegahan abrasi di daerah hulu sungai atau pantai yang bisa saja membawa dampak tidak baik bagi kehidupan masyarakat sekitar.

Tabel 1. Perbandingan Kondisi antara Sebelum dan Sesudah Pelaksanaan KKN PPM

\begin{tabular}{|c|c|c|}
\hline No & $\begin{array}{l}\text { Kondisi } \\
\text { Sebelum } \\
\text { Program }\end{array}$ & $\begin{array}{c}\text { Kondisi Setelah } \\
\text { Program }\end{array}$ \\
\hline 1 & \multicolumn{2}{|c|}{ Pelatihan Software Perkapalan } \\
\hline & $\begin{array}{l}\text { Waktu } \\
\text { pembangunan } \\
\text { kapal lama } \\
\text { Membutuhkan } \\
\text { kurang lebih } 4 \\
\text { bulan untuk } 1 \\
\text { kapal }\end{array}$ & $\begin{array}{l}\text { Waktu } \\
\text { pembangunan } \\
\text { kapal menjadi } \\
\text { lebih cepat ( } 2 \\
\text { bulan untuk } 1 \\
\text { kapal), } \\
\text { pendapatan } \\
\text { menjadi lebih } \\
\text { baik. }\end{array}$ \\
\hline 2 & \multicolumn{2}{|c|}{ Penanaman Mangrove } \\
\hline & $\begin{array}{l}\text { Terjadi abrasi } \\
\text { dan kerusakan } \\
\text { ekosistem } \\
\text { pantai }\end{array}$ & $\begin{array}{l}\text { Mengurangi } \\
\text { abrasi dengan } \\
\text { adanya tanaman } \\
\text { mangrove yang } \\
\text { meredam } \\
\text { hempasan } \\
\text { gelombang } \\
\text { ombak. } \\
\text { Menghasilkan } \\
\text { habitat bagi } \\
\text { organisme } \\
\text { pantai. }\end{array}$ \\
\hline 3 & \multicolumn{2}{|c|}{ Aplikasi Alat Oil Water Separator } \\
\hline & $\begin{array}{l}\text { Limbah sisi } \\
\text { pendingin } \\
\text { mesin kapal } \\
\text { langsung } \\
\text { dibuang dan } \\
\text { mencemari } \\
\text { perairan laut. }\end{array}$ & $\begin{array}{l}\text { Limbah } \\
\text { diproses dengan } \\
\text { alat OWS dan } \\
\text { mengurangi } \\
\text { dampak } \\
\text { pencemaran air } \\
\text { laut. }\end{array}$ \\
\hline
\end{tabular}

\section{KESIMPULAN}

1. Pelaksanaan program ini ditujukan kepada siswa sekolah agar di masa mendatang bisa menerapkan ilmunya dalam pengembangan industri kapal di daerah tersebut. Pendalaman materi dan peningkatan keahlian dalam memanfaatkan software perkapalan perlu dijadikan kurukulum utama. Sehingga keberlangsungan pendidikan software ini dapat dievaluasi dan dikembangkan seiring berjalannya waktu.

2. Pelaksanaan program ini melibatkan tempat wisata di sekitar lokasi KKN. Warga sekitar yang berkunjung ke tempat wisata tersebut diharapkan terbuka pikirannya dan sadar akan pentingnya tanaman mangrove. Penanaman mangrove perlu dijadikan materi yang disampaikan di sekolah agar generasi muda dapat mengetahui manfaatnya serta membudayakannya di masa mendatang.

3. Pelaksanaan program ini diharapkan memberi solusi terhadap pencemaran perairan laut. Selain itu juga memberi kesadaran pada masyarakat terutama nelayan akan pentingnya menjaga kondisi perairan untuk kebaikan bersama, dalam hal ini yaitu menjaga kondisi ekosistem perairan yang menjadi habitat ikan yang ditangkap oleh nelayan.

\section{DAFTAR PUSTAKA}

[1] Arafa, Muhammad., Dr., 2012, "Design of Circular Concrete Tanks", Dept. Civil Eng., The Islamic University of Gaza, Jordan.

[2] Brownell, Lloyd E., Young, Edwin H., 1959, " Process Equipment Design (Vessel design)", U.S. Edition. New York.

[3] Diantoro, Yimi, 2010, "EMAS, Investasi \& Pengolahannya, Pengolahan Emas Skala Home Industry", Penerbit PT Gramedia Pustaka Utama, Jakarta.

[4] Mc Cabe, Warren. L., 1990, "Operasi Teknik Kimia, Jilid 2", Edisi Keempat, Penerbit Erlangga, Jakarta.

[5] Perry, R Green, D.W and Maloneney, J.O, 1984, "Perry's Chemical engineering Handbook 6th Edition", Mc Graw Hill,Tokyo, Japan.

[6] Sukmana, 2002,. "Inventarisasi Mineral Logam Mulia dasar di kabupaten 
Wonogiri, Propinsi Jawa Tengah", SudDin Mineral Logam, Jakarta.

[7] Zulhikman, Meldy; Nurjazuli, Tri Joko, 2013, "Efektivitas Zeolit dan Karbon Aktif Melalui Penyaringan Up Flow dalamMenurunkan Kadar Merkuri (Studi Kasusu di Desa Jendi Kecamatan Selogiri Kabupaten Wonogiri Jawa Tengah)", Volume 2,Nomor 2, April 2013, Jurnal Kesehatan Masyarakat 2013, FKM UNDIP, Semarang. 